\title{
Drug interactions
}

\section{Z Jooma}

Department of Anaesthesia, Charlotte Maxeke Johannesburg Academic Hospital, University of the Witwatersrand, South Africa Corresponding author, email: zainub.jooma@gmail.com

Keywords: drug interactions, anaesthesia, pharmocokinetic, pharmacodynamic, pharmaceutical

Administration of multiple drugs within a short period of time is inevitable in anaesthesia practice, increasing the likelihood of drug interactions with each drug or with patients' chronic medication. Drug interactions can be described as the pharmacological effect of one drug on another drug when administered simultaneously. ${ }^{1}$ The principles of these interactions may be divided into pharmaceutical, which relates to the physicochemical structure or pharmaceutical preparation of a drug; pharmacokinetic (PK), which relates to changes in drug handling in the body; or pharmacodynamic (PD) where drug activity is affected. ${ }^{2}$

\section{Pharmaceutical interactions}

Pharmaceutical interactions occur due to the physical or chemical incompatibility of drugs prior to administration or absorption. ${ }^{2,3}$ Mixing of drugs with carrier fluids which have variable $\mathrm{pH}$ and ion concentrations may cause interactions. For this reason, drugs should not be administered via the same intravenous line as total parenteral nutrition or blood products. Similarly, blood should not be administered in the same line as hypertonic solutions, or solutions containing calcium or glucose. ${ }^{3}$ Other types of pharmaceutical interactions are detailed below.

\section{pH effects}

Drugs in the non-ionised form, which are weak acids or weak bases, are able to move more easily across membranes to exert their effects. Drug formulations of weak acids or bases may damage veins when given intravenously due to their caustic nature, hence certain drugs must be given intramuscularly, e.g. cyclizine or haloperidol. Most drugs are formulated in the ionised form as this allows them to remain stable for longer; weak bases are kept in a solution with a high $\mathrm{pH}$ whereas weak acids are kept in a solution with a low $\mathrm{pH}^{3}$

Mixing of drugs with markedly different $\mathrm{pH}$ values of may cause precipitation. This occurs due to neutralisation and the formation of an insoluble salt, for example mixing sodium bicarbonate and calcium. ${ }^{3}$

\section{Solubility}

Drugs need to be formulated such that they remain stable until the site of action is reached. Thiopentone and dantrolene, for example, cannot be maintained in a stable solution and need to be reconstituted prior to administration and given soon thereafter. Etomidate and lorazepam are formulated with propylene glycol to increase solubility; however this agent may cause metabolic acidosis in high concentrations. Incorporation of a drug into a lipid emulsion is a more favourable pharmaceutical interaction to increase drug solubility thereby avoiding toxic solubilising agents, e.g. propofol and newer formulations of etomidate and diazepam. ${ }^{3}$

\section{Solvent interactions}

Certain drugs require specific preparation to maintain stability. An example would be that of phenytoin and amiodarone which are mixed with ion free solutions such as $5 \%$ dextrose water. ${ }^{3}$ Conversely, insulin is denatured and loses its pharmacological effect when prepared in a dextrose solution. ${ }^{2}$

\section{Photosensitivity}

Drugs such as nimodipine and sodium nitroprusside are light sensitive and therefore require special administration sets to prevent degradation when exposed to light. $^{3}$

\section{Adsorption}

Some drugs bind to plastic compounds in intravenous infusion sets and fluid bags thus necessitating specific delivery equipment, e.g. paraldehyde is administered in a glass syringe and glyceryl trinitrate is administered in polyethylene rather than polyvinyl chloride sets. ${ }^{2}$ Flushing the fluid path with $5-10 \mathrm{ml}$ of solution prior to administration may limit binding sites to reduce this effect. ${ }^{3}$

\section{Phamacokinetic interactions}

PK interactions can be described as the change in the absorption, distribution, metabolism or excretion of one drug by another drug. This type of interaction is difficult to predict and varies between patients. ${ }^{4}$

\section{Absorption}

Intravenous drug administration bypasses absorption problems. ${ }^{1}$ Enterally administered drugs may bind to other drugs 
in the gastrointestinal tract reducing their clinical effects as occurs with activated charcoal. ${ }^{2}$ Similarly, cholestyramine is a bile sequestering agent that may bind to other acidic drugs and thereby affect absorption. ${ }^{5}$ Drugs may also affect gastrointestinal tract transit time altering the effects of other drugs. This is seen with metoclopramide which enhances gastric emptying and increases the absorption of other orally administered drugs. ${ }^{4}$ Changes to $\mathrm{pH}$ levels in the stomach or intestine can affect absorption by altering the non-ionised fraction of drugs. ${ }^{5}$

Local anaesthetic agents are mixed with vasoconstrictors which reduces blood flow to the area of administration and slows absorption. ${ }^{4}$ Drugs administered intramuscularly, subcutaneously or topically are absorbed more slowly under general anaesthesia due to reduced tissue perfusion, making the pharmacokinetics unpredictable. ${ }^{3}$

P-glycoprotein (P-gp) is an ATP-dependent efflux pump that actively transports drugs out cells and it is found on cells lining the endothelium, enterocytes and along the bloodbrain barrier. ${ }^{6}$ In the intestine, P-gp regulates the absorption of drugs and promotes drug excretion. ${ }^{5}$ As a result, drugs that inhibit or enhance P-gp transport mechanisms may result in increased absorption or reduced efficacy of drugs respectively. 5,6 P-gp inhibition can significantly increase the bioavailability of poorly absorbed drugs and manifest drug toxicities in this way, particularly for drugs with narrow therapeutic indices. 5

A number of drugs inhibit P-gp, namely: lignocaine, fluoxetine, statins, macrolides, itraconazole, quinidine, cyclosporine $A$, midazolam, omeprazole, propranolol and verapamil. P-gp is induced by aspirin, rifampicin and trazodone. ${ }^{6}$

\section{Distribution}

Volume of distribution $\left(\mathrm{V}_{\mathrm{d}}\right)$ is the apparent volume into which a drug would need to be dissolved, in order to yield a particular plasma concentration. Simultaneously administered drugs can affect $V_{d}$ through different mechanisms. ${ }^{1}$

Competition for binding sites on plasma proteins, most commonly albumin or alpha $a_{1}$-acid glycoprotein, can lead to the displacement of one drug by another, increasing the free fraction of unbound drug and resulting in a higher $\mathrm{V}_{\mathrm{d}} \cdot{ }^{1}$ This is seen with erythromycin or amiodarone displacing warfarin from its binding site on albumin, increasing the free fraction of warfarin and its clinical effects. ${ }^{4}$ Several other drugs that bind to albumin may result in similar drug interactions, namely: furosemide, phenytoin, valproate, ibuprofen and probenecid. Drug displacement may be a beneficial effect as occurs with the interaction of certain antibiotics and other acidic drugs. Nonsteroidal anti-inflammatory drugs (NSAIDs), such as indomethacin or naproxen, displace penicillin and sulphonamide from its binding site, increasing the free fraction of the antibiotic and thus the antimicrobial activity. ${ }^{3}$

Reduced amounts of plasma proteins, which can occur for physiological or pathological reasons, increase the free fraction of bound drugs and the $V_{d}$. In neonates, alpha $a_{1}$-acid glycoprotein levels are reduced, which increases the free fraction of alfentanil, thereby increasing the respiratory depressant effects. ${ }^{3}$

Drugs that decrease cardiac output will decrease tissue perfusion, thus decreasing both drug delivery and drug redistribution and altering the $V_{d} \cdot{ }^{1}$ Peripheral reservoirs such as muscle and fat become saturated with prolonged infusions. Drugs that have similar distribution properties will compete for binding sites in these reservoirs, altering the $V_{d}$ and concentration of each drug. ${ }^{3}$

\section{Metabolism}

The liver is an important site for metabolism of drugs. Alteration in blood flow to hepatocytes can affect the quantity of drug metabolised. Drugs with high intrinsic clearance which exceeds hepatic blood flow are described as flow dependent, for example lignocaine. Propranolol, noradrenalin and anaesthetic agents reduce hepatic blood flow while isoprenaline increases it, thus altering the half-life of lignocaine. ${ }^{4}$

Prodrugs rely on metabolism by enzymes into the active drug and can remain inactive in the presence of enzyme inhibitors. This is seen with the co-administration of omeprazole and clopidogrel, which reduces the efficacy of clopidogrel. Enzyme inducers will conversely increase the production of active drug from prodrugs and increase the risk of overdose. ${ }^{3}$

Drugs may induce or inhibit enzyme systems and thereby affect the metabolism of other drugs. ${ }^{3}$ Co-administration of drugs metabolised by the same enzyme can also affect the activity and clearance of either drug. ${ }^{7}$

The CYP450 enzymes are most commonly implicated. Enzyme inducers will result in increased clearance of drugs metabolised by the enzyme, and thus a higher dose will be needed to achieve the desired clinical effect. An example of this is rifampicin induction of CYP450, leading to auto-induction of its own metabolism and thus reducing its bioavailability. Enzyme induction can increase toxic effects of drug metabolites, for example the NAPQI metabolite from paracetamol metabolism. The risk of severe liver injury from paracetamol overdose is increased in the presence of drugs that increase its metabolism. Enzyme inducers increase CYP450 activity by increasing enzyme synthesis via DNA transcription, thus the effect of the increased enzyme activity is delayed.?

Enzyme inhibitors will reduce drug metabolism, increasing the substrate drug and increasing the risk of side effects and toxicity. Drugs may be metabolised and inhibited by the same enzyme or may be metabolised by one enzyme and inhibited by another. Unlike induction of enzyme effects, inhibitor effects usually occur immediately.

Common drug interactions with the P450 enzymes and drugs administered in anaesthesia are illustrated in Table I. 


\begin{tabular}{|c|c|c|}
\hline Drug & Inhibitor & Inducer \\
\hline \multicolumn{3}{|l|}{ CYP1A2 } \\
\hline $\begin{array}{l}\text { Ropivacaine } \\
\text { Naproxen }\end{array}$ & $\begin{array}{l}\text { Fluvoxamine } \\
\text { Ciprofloxacin } \\
\text { Cimetidine }\end{array}$ & $\begin{array}{l}\text { Rifampicin } \\
\text { Carbamazepine } \\
\text { Tobacco }\end{array}$ \\
\hline \multicolumn{3}{|l|}{ CYP2C9 } \\
\hline $\begin{array}{l}\text { NSAIDs } \\
\text { Warfarin } \\
\text { Angiotensin receptor blockers } \\
\text { Glipizide, tolbutamide }\end{array}$ & $\begin{array}{l}\text { Isoniazid } \\
\text { Amiodarone } \\
\text { Metronidazole } \\
\text { Fluconazole, voriconazole }\end{array}$ & $\begin{array}{l}\text { Rifampicin } \\
\text { Carbamazepine } \\
\text { Phenytoin } \\
\text { Phenobarbital }\end{array}$ \\
\hline \multicolumn{3}{|l|}{ CYP2D6 } \\
\hline $\begin{array}{l}\text { Codeine } \\
\text { Tramadol } \\
\text { Ondansetron, granisetron } \\
\beta \text {-blockers, antipsychotics, antidepressants }\end{array}$ & $\begin{array}{l}\text { SSRIs: Paroxetine, sertraline, fluoxetine } \\
\text { Amiodarone } \\
\text { Quinidine }\end{array}$ & \\
\hline \multicolumn{3}{|l|}{ CYP2C19 } \\
\hline $\begin{array}{l}\text { Citalopram } \\
\text { Clopidogrel } \\
\text { Diazepam }\end{array}$ & $\begin{array}{l}\text { Fluoxetine, paroxetine } \\
\text { Voriconazole }\end{array}$ & $\begin{array}{l}\text { Rifampicin } \\
\text { Carbamazepine } \\
\text { Phenytoin } \\
\text { Phenobarbital }\end{array}$ \\
\hline \multicolumn{3}{|l|}{ CYP3A4 } \\
\hline $\begin{array}{l}\text { Fentanyl, sufentanil, alfentanil } \\
\text { Midazolam, alprazolam, diazepam } \\
\text { Methylprednisolone, hydrocortisone } \\
\text { Lignocaine } \\
\text { Warfarin, rivaroxaban, apixaban }\end{array}$ & $\begin{array}{l}\text { Clarithromycin, erythromycin } \\
\text { Azole antimycotics } \\
\text { Diltiazem, verapamil } \\
\text { Amlodipine, nifedipine } \\
\text { Amiodarone } \\
\text { HIV protease inhibitors }\end{array}$ & $\begin{array}{l}\text { Rifampicin } \\
\text { Rifabutin } \\
\text { Carbamazepine phenytoin } \\
\text { Phenobarbital } \\
\text { Efavirenz, nevirapine }\end{array}$ \\
\hline
\end{tabular}

NSAIDs - Nonsteroidal anti-inflammatory drugs, SSRI - elective serotonin receptor inhibitors

Other drug interactions may result from interference with drug metabolism. Administration of indirect acting sympathomimetics, e.g. ephedrine or metaraminol with monoamine oxidase inhibitors (MAOls) can displace large amounts of catecholamines from neurotransmitter vesicles and

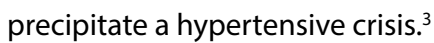

Administration of selective serotonin receptor inhibitors (SSRIs) with drugs that increase serotonin levels can result in serotonin syndrome. This can potentially be caused by any drug that alters the synthesis, release, metabolism or reuptake of serotonin. ${ }^{3}$ The mechanisms and drugs implicated in serotonin syndrome are described in Table II.

\section{Elimination}

Drugs that affect renal perfusion, glomerular filtration rate, tubular function and urinary $\mathrm{pH}$ can alter the elimination of renally excreted drugs. Aminoglycosides are nephrotoxic and may affect the elimination of rocuronium. ${ }^{4}$ Conversely, this type of interaction may be utilised clinically. Alkalinisation of urine by sodium bicarbonate enhances water solubility and promotes the excretion of weak acids in the treatment of aspirin overdose. ${ }^{2,4}$

Table II: Drugs implicated in serotonin syndrome ${ }^{9}$

\begin{tabular}{ll}
\hline Mechanism & Drugs \\
\hline Inhibit serotonin metabolism & MAOIs (phenelzine, moclobemide, selegiline) \\
& Drugs with MAOI activity (methylene blue, hydralazine, linezolid) \\
\hline Enhance serotonin release & Ecstasy, cocaine, amphetamines, fenfluramine \\
& Phenylpiperidine opioids (fentanyl and meperidine) \\
& Oxycodone, tramadol \\
\hline Inhibit serotonin reuptake & SSRIs (paroxetine, sertraline, citalopram, fluoxetine) \\
& SNRIs (venlafaxine and duloxetine) \\
& TCAs (amitriptyline, imipramine, clomipramine, desipramine) Phenylpiperidine opioids and tramadol \\
& Trazodone \\
& Ondansetron and granisetron \\
\hline Direct serotonin agonist & Triptans (sumatriptan, rizatriptan, zolmitriptan) \\
& Ergot alkaloids \\
& $5-$ HT $_{1}$ receptor agonists (clozapine, quetiapine) \\
\hline Increased postsynaptic receptor response & Lithium \\
\hline
\end{tabular}

MAOIs - monoamine oxidase inhibitors, SSRI - elective serotonin receptor inhibitors, SNRI - serotonin and noradrenalin reuptake inhibitor, TCA - tricyclic antidepressants 


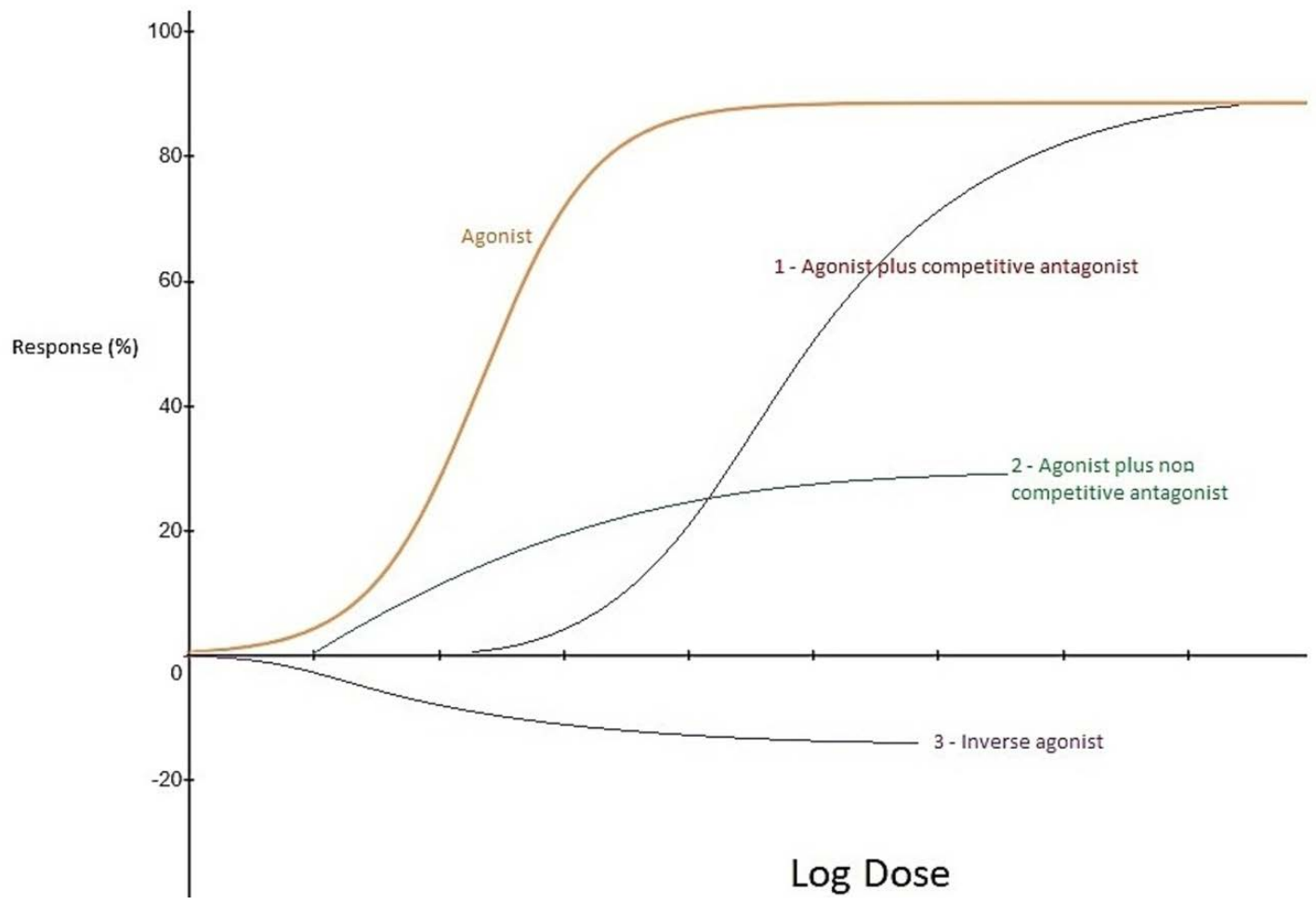

Figure 1: Competitive, non-competitive and inverse antagonism ${ }^{3}$

Drugs that alter cardiac output and pulmonary ventilation may alter the elimination of other drugs and the alveolar concentration of inhalational agents. ${ }^{4}$ Remifentanil causes a decrease in cardiac output, decreasing hepatic and renal blood flow, thus increasing propofol concentrations by reducing elimination. Propofol, however, decreases liver perfusion, and can thereby decrease its own elimination. ${ }^{1}$

\section{Pharmacodynamic interactions}

PD interactions may result in inhibitory, additive, synergistic or potentiation effects, ${ }^{2}$ where each drug may be an agonist or antagonist. ${ }^{3}$ They may occur at the same receptor (direct) or different receptors achieving the same clinical effect (indirect). An example of a direct PD interaction is the treatment of benzodiazepine overdose with flumazenil. Indirect PD interactions can be understood by the effects of neostigmine reversing neuromuscular blockade. Neostigmine does not act directly at the nicotinic receptor but increases acetylcholine concentration, which then competitively displaces the depolarising muscle relaxant. $^{2}$

\section{Inhibitory interactions $1+1<2$}

Antagonistic interactions occur when the effect of a drug reduces the effect of another drug or an endogenous ligand. Inhibitory interactions may be competitive or non-competitive. ${ }^{3}$

A competitive antagonist competes with an agonist for binding to a receptor without activating it, thus it blocks the action of the agonist, e.g. $\beta$-blockers. It affects the amount of agonist required for maximal effect but does not reduce the maximal effect. This is illustrated as the right shift of graph one in Figure 1. Competitive antagonists may be specific or selective. Specific antagonists will bind only to a specific receptor at the effect site irrespective of the concentration. Selective antagonists will preferentially bind to the intended receptor at low concentrations but may bind to other receptors in increasing concentrations. Inverse agonists, illustrated in graph three in Figure 1, are competitive antagonists that bind to receptor sites and produce the opposite effect of an agonist, e.g. naloxone at the $\mu$-opioid receptor. ${ }^{3}$

Non-competitive antagonists result in inhibition of the receptor that cannot be overcome by addition of more agonist. ${ }^{10}$ This can be achieved in two ways. In the first instance, the noncompetitive antagonist binds to allosteric (non-agonist) sites on the receptor, antagonising the effect of the agonist. It does not interfere with agonist binding, but reduces the maximal response of the agonist irrespective of the concentration of agonist present, e.g. ketamine at the $\mathrm{N}$-methyl-D-aspartate (NMDA) receptor. ${ }^{3}$ This effect is illustrated in graph two in

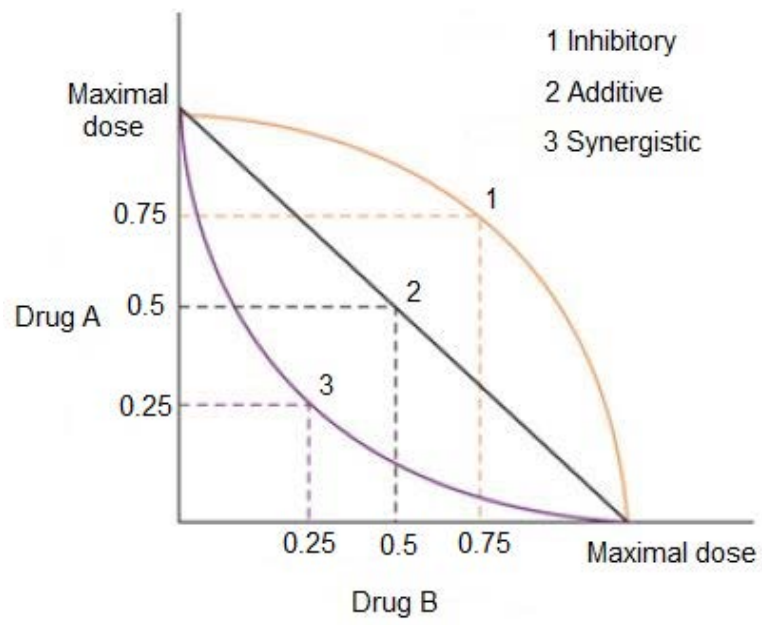

Figure 2: Isobologram illustrating inhibitory (1), additive (2) and synergistic (3) drug interactions ${ }^{2}$ 
Figure 1. In the second instance, the non-competitive antagonist binds to the agonist binding site (e.g. an enzyme or receptor) permanently inactivating it. Any downstream effects will only be restored once the enzyme or receptor has been re-synthesised. ${ }^{3}$

A clinical example of non-competitive antagonism can be seen in patients with myasthenia gravis. Irreversible binding of the antibody to the acetylcholine receptor permanently inactivates it, reducing the number of binding sites for muscle relaxants to act. Depolarising muscle relaxants are less effective as the small number of binding sites results in slower depolarisation. In contrast, non-depolarising muscle relaxants rapidly saturate the small number of available receptors even with low concentrations of the muscle relaxant. ${ }^{3}$

\section{Additive interactions $1+1=2$}

This occurs when drugs with similar effects augment the activity of each other at submaximal concentrations. Reduction of the dose of each drug reduces the side effects while achieving the desired clinical effect. ${ }^{3}$ Co-induction is an example of this; a small dose of an opioid or benzodiazepine reduces the amount of induction agent required. ${ }^{2}$

\section{Synergistic interactions $1+1>2$}

Synergy occurs when two drugs given at submaximal doses result in an effect that is greater than an additive effect only (supraadditive). ${ }^{11}$ The drugs have similar clinical effects but different mechanisms. ${ }^{2}$ Examples of this are the co-administration of synergistic antimicrobial agents which are used to treat severe infections, as well as the combination of opioids and benzodiazepines which can cause greater respiratory depression than the use of each agent independently. ${ }^{3}$

The nature of interactions between different drugs can be illustrated by isobolograms. This is illustrated in Figure 2 .

\section{Potentiation}

This is another form of a PD interaction where one drug increases the effect of another drug each having different mechanisms of action. ${ }^{11}$ An example would be that of probenecid, which reduces the renal excretion of penicillin, thus increasing the antimicrobial effect without having any antimicrobial activity itself. $^{2}$

\section{Conclusion}

Specific drug interactions are numerous and difficult to memorise; however, a number of electronic drug interaction applications are available for this purpose. Drug interactions are inevitable in anaesthesia and sound knowledge of the underlying core principles is important to recognise potential interactions to ensure optimal drug delivery and to avoid adverse effects.

\section{Disclosure}

This review article was presented at the FCA I Anaesthesia Refresher course.

\section{Conflict of interest}

The author declares no conflict of interest.

\section{Funding source}

None.

\section{ORCID}

\section{Z Jooma iD https://orcid.org/0000-0002-1036-8744}

\section{References}

1. Van den Berg JP, Vereecke HEM, Proost JH, et al. Pharmacokinetic and pharmacodynamic interactions in anaesthesia. A review of current knowledge and how it can be used to optimize anaesthetic drug administration. $\mathrm{Br}$ J Anaesth. 2017;118:44-57. https:/doi.org/10.1093/bja/aew312.

2. Drug interaction. In: Peck TE, Hill SA, Williams M, editors. Pharmacology for Anaesthesia and Intensive Care. 3rd ed. New York: Cambridge University Press; 2008. p. 40-4.

3. Hodgson RE. Drug interactions relevant to anaesthesia. In: Milner A, Welch E, editors. Applied pharmacology in anaesthesiology and critical care. 2nd ed. China: Everbest Printers; 2019. p. 63-77.

4. Corrie K, Hardman JG. Mechanisms of drug interactions: pharmacodynamics and pharmacokinetics. Anaesth Intensive Care Med. 2017;18:331-4. https:/doi. org/10.1016/j.mpaic.2017.04.006.

5. Palleria $C$, Di Paolo $A$, Giofrè $C$, et al. Pharmacokinetic drug-drug interaction and their implication in clinical management. J Res Med Sci. 2013;18:601-10.

6. Belii A, Belii N. Drug interactions in anaesthesia practice: a basic review for residents. Anestezjologia i Ratownictwo. 2010;4:99-110. Available from: https:// www.semanticscholar.org/paper/Drug-interactions-in-anaesthesia-practice\%3A-a-basic-Bel\%C3\%AEi-Bel\%C3\%AEi/9215cceb19cdc207417c94c8e767b9c2d 153b8b0. Accessed 22 February 2020.

7. Brennan B. Cytochrome P450. Part I Anaesthesia Refresher Course. University of Cape Town. 2017. p. 20:1-8. Available from: http://www.anaesthesia.uct.ac.za/ sites/default/files/image_tool/images/93/20-The\%20Cytochrome\%20P450\%20 System\%20\%28B\%20Brennan\%29.pdf. Accessed 18 February 2020.

8. Spriet I, Meersseman W, De Hoon J, et al. Mini-series: II. Clinical aspects. Clinically relevant CYP450-mediated drug interactions in the ICU. Intensive Care Med. 2009;35:603-12. https:/doi.org/10.1007/s00134-008-1383-2.

9. Bartakke A, Corredor C, Van Rensburg A. Serotonin syndrome in the perioperative period. Br J Anaesth Educ. 2020:10-7. https:/doi.org/10.1016/j. bjae.2019.10.003.

10. Lambert DG. Drugs and receptors. Cont Educ Anaesthes Crit Care Pain. 2004;4:181-4. https:/doi.org/10.1093/bjaceaccp/mkh049.

11. Williams J. Enzyme inhibition and induction. Anaesth Intensive Care Med. 2008;9:165-6. https:/doi.org/10.1016/j.mpaic.2008.02.004. 